\title{
Daya Tahan Parahyangan TV Sumedang Sebagai TV Lokal Di Tengah Perkembangan Digital
}

\author{
Ade Nasihudin Al Ansori dan Andika Vinianto Adiputra \\ Liputan6.com, Jakarta, Indonesia \\ Email: adenasihudina@gmail.com
}

\begin{abstract}
The exceedingly amount of local broadcasting institutions should be conjoined by the ablity of the media to maintain its existence. This ability is required considering the fact that competition comes from not only other local media, but also from the national media. This study aims to determine the management strategy of PAR TV in maintaining its existence and becoming one of the local media that remains active to this day. The method used in this study is a qualitative research method with descriptive techniques. The object of this research is Parahyangan TV (PAR TV), a local television station located in Sumedang. The results show that the business strategies used by PAR TV are (1) focusing on local wisdom content, (2) collaborating with local governments, (3) improving broadcast quality by conducting regular training of employees, (4) establishing good communication with the center, and (5) determine the targets to be achieved. The conclusion of this research is the main strategy carried out by PAR TV in the form of focusing its programs on content containing art, culture, and local wisdom.
\end{abstract}

Keywords: business strategy, culture, local content, local media, local wisdom

\begin{abstract}
Abstrak
Menjamurnya lembaga penyiaran di daerah tentunya harus disertai kemampuan media dalam mempertahankan keberadaannya. Mengingat persaingan yang tinggi tidak hanya antar media lokal tapi juga media swasta nasional. Penelitian ini bertujuan untuk mengetahui strategi manajemen PAR TV dalam mempertahankan eksistensinya sehingga mereka menjadi salah satu media lokal yang tetap aktif hingga kini. Metode yang digunakan dalam penelitian ini adalah metode penelitian kualitatif dengan teknik deskriptif. Objek penelitian adalah stasiun TV lokal di Sumedang, Parahyangan TV (PAR TV). Hasil penelitian ini adalah, strategi bisnis yang digunakan PAR TV adalah (1) fokus terhadap konten kearifan lokal, (2) melakukan kerjasama dengan pemerintah daerah, (3) meningkatkan kualitas siaran dengan melakukan pelatihan rutin terhadap karyawan, (4) menjalin komunikasi yang baik dengan pusat, dan (5) menentukan targettarget yang harus dicapai. Kesimpulan dari penelitian ini adalah strategi utama yang dilakukan PAR TV berupa pemfokusan pada program dengan konten bermuatan seni, budaya, dan kearifan lokal.
\end{abstract}

Kata kunci: budaya, kearifan lokal, konten lokal, media lokal, strategi bisnis

\section{PENDAHULUAN}

Sumedang memiliki tiga stasiun televisi yang masih aktif yaitu Parahyangan TV, SKTV, dan JMTV. Sebelumnya, sempat ada SportoneTV namun mereka tidak berhasil mempertahankan eksistensinya di Sumedang dan pada akhirnya ditutup. Dari kasus tersebut, lahir sebuah pertanyaan "Apakah maraknya lembaga penyiaran yang lahir di kota-kota kecil diimbangi dengan kemampuan mereka untuk bertahan?”. Salah satu cara untuk mengetahui jawabannya dapat dilakukan dengan penelitian tentang bagaimana strategi manajemen bisnis televisi lokal di Sumedang dalam mempertahankan eksistensinya.

Korespondensi: Liputan6.com Jl. RP Suroso no 18 Menteng, Jakarta Pusat, Indonesia, Email: adenasihudina@gmail.com

Menyerahkan: Oktober 2019, Diterima: November 2019, Terbit: Januari 2020 ISSN: 2549-0559 (cetak), ISSN: 2549-1946 (online), Website: http://jurnal.unpad.ac.id/kajian-jurnalisme 
Tak dapat dipungkiri, tujuan utama lembaga-lembaga penyiaran komersial atau swasta adalah untuk mendapatkan keuntungan bisnis. Berbagai strategi manajemen media dibangun untuk menunjang eksistensi dan keuntungan bisnis. Diantaranya adalah melalui pengelolaan manajemen produk. Kemampuan sebuah media untuk mensinergikan antara format, harga, kualitas, pengaruh konten serta pemahaman akan karakteristik kelompok khalayak yang dibidik akan memperkuat daya tarik media tersebut (Viranda, Hidayat, \& Yudhapramesti, 2019).

Parahyangan $T V$ adalah salah satu dari tiga televisi swasta lokal yang berdiri di Sumedang. Parahyangan TV yang lebih dikenal dengan sebutan PAR TV ini adalah televisi tertua jika dibandingkan dengan televisi lainnya yaitu SKTV Sumedang dan JMTV. Berdiri pada 2011 dan memiliki izin siaran pada 2012. Sedangkan, SKTV berdiri pada 2018 dan JMTV pada 2015. Dengan demikian, PartTV dapat disebut sebagai televisi pertama yang mengudara di Kota Sumedang. PAR TV memiliki tag line "TV na Urang Parahyangan" yang artinya "TV-nya Orang Priangan".

Dalam situs resmi PAR TV disebutkan ada 14 program yang ditayangkan yaitu; Expressi, Beja Keur Balarea, Ini Berita, Ruang Inspirasi, Tembang Tatar Sunda, Muda (Musiknya Anak Muda), Banyolan Anak Gaul (Balaga), Ngaprak Ngacaprak, Nyucruk Galur, Majelis Ilmu, Filler Islam, Budaya Urang, Celetak Celetuk, Ngalungtik. Dari 14 program PAR TV, delapan di antaranya adalah program bermuatan lokal, kedaerahan, menyangkut seni dan budaya Sunda. Hal ini menimbulkan pertanyaan, banyaknya program $P A R T V$ yang fokus pada budaya Sunda apakah menjadi salah satu strategi mereka dalam bertahan, mengingat Sumedang memiliki jargon "Puseur Budaya Sunda" yang artinya pusat budaya Sunda (Thohir, 2013).

PAR TV dapat membuktikan kualitas mereka dalam menyajikan program bermuatan seni dan budaya lokal melalui penghargaan-penghargaan yang mereka raih. Pada 2013 PAR $T V$ berhasil membawa pulang penghargaan program siaran terbaik kategori pertunjukan seni budaya tradisi televisi dengan program Budaya Urang (Imanuddin, 2016) dalam ajang Komisi Penyiaran Indonesia Daerah (KPID) Award. Pada 2014, dalam ajang yang sama PAR TV berhasil meraih penghargaan kategori Iklan Layanan Masyarakat atau ILM terbaik. Sedangkan, pada 2015 masih di ajang yang sama, PAR TV kembali menyabet penghargaan kategori ILM terbaik tema lingkungan. Pada 2017, PAR TV berhasil masuk nominasi kategori feature televisi dan hiburan seni budaya lokal televisi. Tahun lalu PAR TV kembali masuk nominasi kategori feature televisi dengan judul Aya Naon (Hadisaputro, 2018).

Selain dikenal sebagai TV tertua, fokus, dan berprestasi, $P A R T V$ juga merupakan televisi di Sumedang dengan jangkauan yang paling luas. Menurut humas PAR TV Soni, jangkauan siaran PAR TV dapat mencapai perbatasan Garut, Tasikmalaya, Majalengka, Kuningan, dan Cirebon. Sedangkan menurut editor di SKTV Fahmi Amirullah, jangkauan SKTV dapat mencapai Majalengka dan Kuningan saja. Mantan karyawan JMTV Septian Mulyana menyebutkan, jangkauan $J M T V$ hanya di satu kecamatan yaitu Kecamatan Cimalaka saja. Sempitnya cakupan wilayah siaran $J M T V$ disebabkan penggunaan frekuensi ilegal.

Konsep yang digunakan dalam penelitian ini adalah model bisnis kanvas dari Alexander Osterwalder, analisis SWOT, dan teori Hierarchy of Influence dari Shoemaker.

\section{METODE}

Metode yang digunakan dalam penelitian ini adalah metode penelitian kualitatif agar peneliti dapat meninjau secara mendalam hal-hal penting yang harus diuraikan. Denzin dan Lincoln (1994) dalam (Herdiansyah, 2010, p.7) menerangkan, penelitian kualitatif digunakan untuk mencapai pemahaman mendalam mengenai sebuah organisasi atau suatu peristiwa khusus daripada mendeskripsikan permukaan sampel besar dari populasi. 
Peneliti menggunakan studi deskriptif agar dapat menggambarkan hasil temuan di lapangan dengan apa adanya. Menurut (Sugiyono, 2010, p. 15), penelitian kualitatif deskriptif merupakan sebuah metode yang didasari filsafat positivisme yang digunakan untuk meneliti kondisi objektif secara murni seperti keadaan di lapangan. Dalam metode ini peneliti berperan sebagai instrumen kunci yang harus bersentuhan dengan subjek penelitian agar dapat menggambarkan fakta secara mendalam dan apa adanya.

Teknik pengumpulan data yang digunakan adalah wawancara mendalam, observasi, dan studi dokumen. Menurut Robert K. Yin, bukti atau data yang diperlukan untuk studi kasus terdiri dari enam sumber, yaitu: dokumen, rekaman arsip, wawancara, pengamatan langsung, observasi partisipan, dan perangkat-perangkat fisik (Yin, 1996, p. 101). Sedangkan, teknik analisa data yang digunakan adalah dari Miles dan Huberman. Ada empat upaya yang perlu dilakukan dalam pengolahan data dari Miles dan Huberman yaitu: (1) pengumpulan data, (2) reduksi data, (3) penyajian data, dan (4) simpulan dan verifikasi. Peneliti juga menggunakan teknik triangulasi guna memperkaya data yang akan didapatkan. Peneliti ingin mewawancarai berbagai pihak guna mendapatkan data yang lengkap. Mulai dari pihak PAR TV, pihak SKTV, JMTV, TVRI Jawa Barat, Bandung TV, dan tanggapan dari pihak Komisi Penyiaran Indonesia Daerah (KPID) terkait penghargaan yang mereka berikan kepada PAR TV.

Objek dalam penelitian ini adalah $P A R T V$ terkait strategi manajemen bisnis, produksi, dan peningkatan kualitas siarannya. Sedang Subjek penelitian ini antara lain; Windu Mandela M, Pd., Produser PAR TV Sumedang, Soni Staf Hubungan Masyarakat dan Marketing PAR TV Sumedang, Sofwan Efendi Direktur Utama SKTV Sumedang, Fahmi Amirullah Editor SKTV Sumedang, Septian Mulyana mantan MCR JMTV Sumedang, William Staf SDM Bandung TV, dan Aef Wahyudin Ketua Pelaksana KPID Awards.

Berdasarkan data yang dimiliki, peneliti ingin mengetahui strategi manajemen bisnis, produksi program, dan peningkatan kualitas siaran yang dilakukan PAR TV sehingga dapat bertahan hingga kini.

\section{HASIL PENELITIAN DAN PEMBAHASAN}

\section{Dari Segi Bisnis}

PAR TV dalam mempertahankan eksistensinya tentu saja melakukan beberapa strategi untuk meraup keuntungan namun di waktu bersamaan juga mendapatkan perhatian dari khalayak. Dilihat dari sisi bisnis PAR TV berhasil menjadi TV lokal Sumedang yang sukses mengendalikan keuangan dan mensejahterakan pegawainya. Pernyataan ini didapat dari hasil wawancara dengan Windu Mandela, Produser PAR TV. Ia mengatakan, pendapatan karyawan PAR TV lebih besar dari pendapatan karyawan TV lokal lainnya di Sumedang. Dilihat dari UMK (Upah Minimum Kabupaten) Sumedang pada 2019 yaitu sebesar Rp 2.893.074,72 (Agus, 2019), dapat dikira-kira pendapatan karyawan $P A R T V$ berada di kisaran nominal tersebut. Sedangkan, Windu tidak berkenan menyebutkan nominal pastinya.

Lebih rinci lagi peneliti menggunakan model bisnis kanvas dari Alexander Osterwalder. Konsep ini menjelaskan alasan rasional mengenai bagaimana sebuah organisasi menciptakan, menyalurkan, dan mendapatkan nilai. Model bisnis dapat dijabarkan melalui sembilan dasar pembangun yang menunjukkan pemikiran logis sebuah perusahaan dalam mendapatkan uang. Sembilan elemen tersebut sudah mencakup empat unsur utama dalam sebuah bisnis yaitu: pelanggan, tawaran, infrastruktur, dan cara mempertahankan keuangan(Osterwalder, 2010). Berikut model bisnis kanvas $P A R T V$ jika disajikan dalam bentuk kanvas atau matriks: 
Volume 03 Nomor 02 Tahun 2020

DOI: $10.24198 /$ jkj.v3i2.23793

Tabel 1 .Matriks Model bisnis kanvas PARTV

\begin{tabular}{|c|c|c|c|c|c|}
\hline \multirow{2}{*}{$\begin{array}{l}\text { KEY PARTNERS } \\
\text { - Event organizer } \\
\text { - Pemerintah Daerah } \\
\text { Sumedang } \\
\text { - Pemerintah Daerah } \\
\text { Majalengka } \\
\text { - Lembaga pendidikan } \\
\text { - Seniman-seniman } \\
\text { Sunda }\end{array}$} & $\begin{array}{l}\text { - Produksi program } \\
\text { - produksi iklan dan } \\
\text { liputan berbayar }\end{array}$ & \multirow{2}{*}{\multicolumn{2}{|c|}{$\begin{array}{l}\text { VALUE } \\
\text { PREPOSITIONS } \\
\text { - Nilai kedekatan } \\
\text { - informatif } \\
\text { - edukatif } \\
\text { - hiburan } \\
\text { - interaktif } \\
\text { - realitas } \\
\text { - muda } \\
\text { - berkelanjutan }\end{array}$}} & $\begin{array}{l}\text { CUSTOMER } \\
\text { RELATIONSHIPS } \\
\text { - self-service untuk } \\
\text { khalayak } \\
\text { - personal assistance } \\
\text { untuk pengiklan }\end{array}$ & \multirow{2}{*}{$\begin{array}{l}\text { CUSTOMER } \\
\text { SEGMENT } \\
\text { - masyarakat } \\
\text { Parahyangan } \\
\text { - usia 20-50 tahun } \\
\text { - golongan ekonomi } \\
\text { menengah ke bawah } \\
\text { seperti buruh dan } \\
\text { petani }\end{array}$} \\
\hline & $\begin{array}{l}\text { KEY } \\
\text { RESOURCES } \\
\text { - Fisikal: fasilitias } \\
\text { kantor dan alat-alat } \\
\text { produksi yang cukup } \\
\text { - Intelektual: Branding } \\
\text { TV seni, budaya, dan } \\
\text { kearipan lokal } \\
\text { - SDM: } 23 \text { orang }\end{array}$ & & & $\begin{array}{l}\text { CHANNELS } \\
\text { - Saluran televisi } 23 \\
\text { UHF } \\
\text { - Sosial media: } \\
\text { Instagram, twitter, } \\
\text { youtube, facebook }\end{array}$ & \\
\hline \multicolumn{3}{|c|}{$\begin{array}{l}\text { COST STRUCTURE } \\
\text { - Cost driven, menekan biaya produksi seminimal mungkin }\end{array}$} & \multicolumn{3}{|c|}{$\begin{array}{l}\text { REVENUE STREAMS } \\
\text { - Tipe transaksi satu kali bayar dari iklan dan liputan } \\
\text { berbayar }\end{array}$} \\
\hline
\end{tabular}

Sumber: Peneliti

Sembilan elemen Model Bisnis Kanvas yang dirumuskan oleh Alexander dan Yves adalah:

\section{Costumer Segment}

PAR TV memilih segmentasi khalayak usia 20 hingga 50 tahun yang merupakan penduduk Parahyangan yaitu Sumedang dan sekitarnya. PAR TV juga mempertimbangkan latar belakang khalayaknya yaitu dari kalangan menengah ke bawah seperti petani dan buruh. Pemilihan ini tepat karena adanya nilai proximity antara cakupan siaran dengan sasaran khalayak. Dilihat dari sisi kebutuhan khalayak, PAR $T V$ memberikan porsi sajian hiburan yang lebih banyak dibanding sajian lainnya. Sejalan dengan khalayaknya yang kebanyakan berprofesi sebagai petani dan buruh yang setelah melakukan aktifitas berat sehari-hari tentunya membutuhkan hiburan di rumah. Terbukti dengan tayangan-tayangan hiburan PAR TV seperti Cangehgar, Celetak-celetuk, dan Bentar yang ditayangkan pada waktu santai di malam hari kisaran pukul 19:00 hingga 22:00.

Di sisi lain, masyarakat menengah ke bawah umumnya hanya bisa dijangkau dengan saluran sederhana seperti saluran televisi non-digital. Hal ini sesuai dengan PAR TV yang memberikan tayangan melalui saluran tv non-digital. $P A R T V$ yang memberikan tayangan gratis tentunya akan banyak diminati oleh khalayak dengan golongan ekonomi menengah ke bawah dan tak akan memilih televisi berbayar.

PAR TV menggunakan tipe mass market atau pasar massa. Tipe ini memfokuskan nilai proposisi, saluran, dan hubungan pelanggan pada suatu khalayak besar yang memiliki kebutuhan dan permasalahan yang sama. Tipe ini banyak ditemukan dalam model bisnis sektor elektronik. (Osterwalder 2010:21).

\section{Value Proposition}

Nilai yang diberikan PAR TV pada pelanggan atau khalayak adalah nilai kedekatan, informasi, hiburan, dan pendidikan yang lebih banyak mengandung unsur pelestarian seni, budaya, dan kearifan lokal. Masalah pelanggan atau pengiklan yang dapat dibantu oleh PAR TV adalah pembuatan dan penyiaran iklan terkait kegiatan atau produk yang dimiliki pengiklan. Kebutuhan yang dapat dipenuhi oleh $P A R T V$ adalah kebutuhan pengetahuan, hak ingin tahu 
DOI: $10.24198 /$ jkj.v3i2.23793

dan diberitahukan mengenai segala informasi teraktual yang terjadi di lingkungannya. Selain itu, kebutuhan akan hiburan pun dipuaskan dengan program-program yang diberikan PAR TV. Bagi pengiklan, $P A R T V$ dapat membuatkan program iklan sesuai keinginan. Bagi khalayak, $P A R T V$ dapat memberikan program-program lokal yang lebih beragam daripada televisi lokal lainnya di Sumedang.

\section{Channels}

Value proposition tadi disampaikan kepada pelanggan melalui komunikasi, distribusi, dan saluran-saluran penunjang. (Osterwalder, 2010:17). Dalam hal ini, PAR TV menggunakan saluran televisi 23 UHF yang dapat diakses melalui layar kaca non-digital. Selain itu, PAR TV juga menggunakan beberapa sosial media untuk memberitahukan kepada warganet mengenai kegiatan-kegiatan mereka. PAR $T V$ dalam pemanfaatan salurannya dapat dijabarkan sebagai berikut:

PAR TV membuat pelanggan sadar akan produknya dengan melakukan penyiaran setiap hari dan promosi melalui media sosial. PAR TV berupaya menyediakan kontak di situs webnya untuk menerima pesan-pesan dari siapa pun yang ingin memberi masukan. $P A R T V$ menayangkan program lokal yang beragam dengan kualitas yang baik agar khalayak lebih memilih menonton $P A R T V$ dibanding televisi lokal lainnya. Untuk pengiklan, PAR TV menyediakan program berbayar dan promo-promo tarif iklan di hari-hari tertentu. Nilai proposisi disapaikan dengan tayangan program yang dekat di hati pemirsa. Lebih banyak menggunakan bahasa daerah dan menjunjung tinggi profesionalitas dan lokalitas. PAR TV melakukan kerjasama yang baik dengan pemerintah daerah dan khalayak Sumedang, serta senantiasa melakukan kerjasama di bidang pendidikan dengan membuka pelayanan praktik kerja lapangan bagi siswa dan mahasiswa. Dengan demikian, PAR TV mendapatkan dukungan yang baik dari sekolah dan masyarakat terkait. Sejauh ini PAR TV memiliki akun sosial media Facebook, Instagram, Twitter, Youtube, dan Situs Web.

\section{Costumer Relationships}

Berdasarkan wawancara dan observasi, $P A R T V$ menerapkan tipe hubungan self-service untuk khalayak dan personal assistance untuk pengiklan. Menurut Alexander dan Yves self-service adalah hubungan sebuah perusahaan dengan pelanggan secara tidak langsung. Perusahaan menyediakan hal-hal yang dibutuhkan pelanggan untuk memenuhi kebutuhannya sendiri. Dengan kata lain, $P A R T V$ menyediakan tontonan dan tayangan kepada khalayaknya tanpa ada pertemuan secara langsung terlebih dahulu. Pelanggan dapat menonton tayangan yang disiarkan PAR TV di rumah masing-masing dan memenuhi kebutuhan akan informasi, pendidikan, dan hiburannya. Sedangkan, tipe hubungan personal assistance dilakukan PAR TV kepada pengiklan. Tipe ini berupa hubungan yang berdasar pada interaksi kedua belah pihak. Pengiklan dapat berbicara langsung atau melalui media untuk menyampaikan kebutuhannya.

\section{Revenue Streams}

Revenue Streams atau aliran pendapatan adalah uang yang didapatkan dari pelanggan. Umumnya, PAR TV menggunakan tipe satu kali pembayaran dalam satu proyek iklan. Misal, penayangan iklan 15 kali yang dibayar di awal sebanyak Rp 15.000.000 secara lunas. Pembayaran tidak dilakukan setiap kali iklan ditayangkan.

Dalam menjalankan revenue streams, PAR TV menyediakan jasa iklan bagi para pelanggan. Aliran pendapatan didapat dari jasa mengiklankan beberapa produk atau kegiatan khusus yang dipesan langsung oleh pelanggan. Nilai yang mereka tawarkan adalah kedekatan dengan pasar, harga murah, shooting iklan gratis, penayangan tepat waktu, kualitas iklan yang 
baik, dan pilihan durasi hingga satu jam. Jasa iklan tersebut dapat dibayar oleh pelanggan secara langsung atau pun melalui transfer bank sesuai keinginan pelanggan. Pengaruh aliran pendapatan dari iklan ini sangat besar bagi pendapatan keseluruhan PAR TV mengingat iklan adalah pendapatan utama $P A R T V$.

Pihak PAR TV tidak memberikan nominal pasti mengenai pendapatan per hari atau per bulan. Namun, mereka memberikan tarif-tarif iklan dan waktu siaran perhari. Dari data-data itu dapat dibuat perkiraan pendapatan $P A R T V$ Sumedang. Jika digambarkan, PAR TV memiliki waktu tayang dari pukul 01:00-23:00 atau 23 jam per hari.

Diumpamakan 23 jam itu digunakan untuk menayangkan 23 program yang masingmasing memiliki waktu tayang sekitar 30 sampai 60 menit. Dalam satuan durasi 30 menit satu program dibagi menjadi empat segmen dan dijeda dengan iklan. Iklan per segmen memiliki durasi 30 detik dengan tarif Rp 95.000. dalam satu program berdurasi 30 menit, total iklan ada empat dengan durasi total 2 menit. Jadi satu program berdurasi 30 menit dapat menghasilkan Rp 380.000. Dalam satu hari 23 jam, jika diubah dalam menit maka totalnya 1.380 menit. Jumlah menit ini dibagi lagi 30 maka hasilnya 46. Untuk mengetahui pendapatan total dalam sehari maka Rp 380.000 harus dikalikan 46 yang hasilnya $\mathrm{Rp}$ 17.480.000. Jumlah ini tentunya belum termasuk liputan berbayar durasi 15-60 menit.

Pertanyaan: Berapa pendapatan PAR TV Sumedang?

Diketahui:

1. Jam tayang= 23 jam, 1 jam 60 menit, $60 \times 23=1.380$ menit.

2. Jumlah jam tayang per 30 menit $=$ Jam tayang $: 30=1.380: 30=46$

3. Pembagian segmen $=4$ segmen

4. Iklan dalam satu segmen $=30$ detik

5. Tarif iklan 30 detik= Rp 95.000

6. Iklan dalam satu segmen $\mathrm{x}$ pembagian segmen $=30 \mathrm{x} 4=120$

7. Iklan dalam 30 menit program $=120$ detik $=2$ menit.

8. Jumlah hari dalam satu minggu $=7$

9. Jumlah hari dalam satu bulan $=30$

10. Tarif liputan berbayar 15 menit $=$ Rp 1.000 .000

11. Tarif liputan berbayar 30 menit $=\mathrm{Rp} 3.000 .000$

12. Tarif liputan berbayar 60 menit $=\operatorname{Rp} 5.000 .000$

13. Jumlah tarif liputan berbayar $=\mathrm{Rp} 9.000 .000$

Perhitungan:

1. Pendapatan dalam 30 menit program $=$ tarif iklan 30 detik $x$ pembagian segmen $=\mathrm{Rp}$ $95.000 \times 4=\operatorname{Rp} 380.000$

2. Pendapatan per hari hanya iklan $=$ Pendapatan dalam 30 menit program $\mathrm{x}$ jam tayang per 30 menit $=$ Rp $380.000 \times 46=$ Rp. 17.480 .000$.

3. Pendapatan per minggu hanya iklan $=$ Pendapatan satu hari $\mathrm{x}$ Jumlah hari $=\mathrm{Rp}$. $17.480 .000 \times 7=\operatorname{Rp} 122.360 .000$

4. Pendapatan per bulan hanya iklan = Pendapatan per hari hanya iklan $\mathrm{x}$ jumlah hari dalam satu bulan $=$ Rp. $17.480 .000 \times 30=$ Rp 524.400.000

5. Jika setiap harinya $P A R T V$ memiliki program berbayar durasi 15 menit, 30 menit, dan 60 menit maka pendapatan pun bertambah.

6. Pendapatan per hari dengan lip berbayar $=$ Pendapatan per hari hanya iklan + Jumlah tarif liputan berbayar $=$ Rp 17.480.000 + Rp 9.000.000 = Rp 26.480.000

7. Pendapatan per minggu dengan lip berbayar $=$ Pendapatan per hari dengan lip berbayar $\mathrm{x}$ jumlah hari dalam satu minggu $=\mathrm{Rp} 26.480 .000 \times 7=\mathrm{Rp} 185.360 .000$ 
8. Pendapatan per bulan dengan lip berbayar $=$ Pendapatan per hari dengan lip berbayar $\mathrm{x}$ jumlah hari dalam satu bulan $=\mathrm{Rp} 26.480 .000 \times 30=\mathrm{Rp} 794.400 .00$

Jadi perkiraan pendapatan per bulan $P A R T V$ yang didapatkan hanya dari iklan adalah Rp 524.400.000. Sedangkan, perkiraan pendapatan $P A R T V$ dalam satu bulan jika ditambah liputan berbayar adalah sebesar Rp 794.400.000. Hasil ini dihitung dan didapatkan berdasar tarif-tarif iklan yang ditentukan oleh pihak $P A R T V$. Data mentah tentang tarif iklan didapatkan dari wawancara bersama Staf Hubungan Masyarakat sekaligus marketing PAR TV bernama Doni.

Jumlah ini menunjukkan, $P A R T V$ adalah televisi lokal yang tujuan utamanya adalah bisnis. PAR TV berusaha melayani pengiklan sebaik mungkin dan tetap berusaha menampilkan yang terbaik untuk khalayak. Menurut pengamatan peneliti, PAR TV adalah televisi lokal yang memihak pada pengiklan dan hal ini dapat melukai independensi. Dilihat dari berbagai iklan yang ditampilkan di $P A R T V$ tak terkecuali iklan berbau kampanye. Menurut wawancara dengan Soni staf marketing PAR TV, mereka memang acap kali melakukan kerjasama dengan pihak partai politik guna mengiklankan kandidatnya.

Hal ini sejalan dengan penelitian berjudul Kebijakan Lembaga Penyiaran Lokal Jawa Barat Dalam Pengelolaan Program Siaran Pemilihan Gubernur Tahun 2013. Penelitian ini ditulis Dekan Fakultas Ilmu Komunikasi Universitas Padjadjaran, Dadang Rahmat Hidayat dan dosen lainnya pada 2013. Penelitian ini menelaah tentang fenomena pemilukada yang menggunakan saluran media massa untuk mengiklankan kandidatnya. Fenomena ini dianggap menarik karena media massa yang menyiarkan iklan semacam itu akan sulit mempertahankan independensinya. Hasil penelitian menunjukan banyaknya lembaga penyiaran daerah Jawa Barat yang berorientasi pada kepentingan bisnis. Mereka tetap menyiarkan kampanye tersebut dengan seimbang, tidak berpihak, dan tidak melanggar namun tetap tergantung pada kekuatan finansial kandidat.

Dalam penelitian ini disebutkan, $P A R T V$ mengaku berkoordinasi dengan lembaga berwenang mengenai penyiaran program Pemilukada Jabar 2013 dengan hadir dalam sosialisai yang diadakan KPU dan KPID. Sosialisasi internal juga dilakukan guna memberikan pengetahuan kepada $P A R T V$ mengenai pedoman penyiaran berbau Pemilukada. PAR TV mengaku menggunakan arahan tersebut guna menyeleksi iklan yang datang dari tim sukses kandidat (Hidayat, Dadang Rahmat, Ahmad A. Basith, 2017).

\section{Key Resources}

Sumber kunci ini meliputi aspek fisik, intelektual, SDM, dan keuangan. PAR TV memiliki sumber kunci sebagai berikut: Secara fisikal, $P A R T V$ memiliki gedung dua lantai yang dilengkapi peralatan liputan seperti kamera, mikrofon, komputer, wif, tripod, alat rekam, pemancar, ruang kerja, dan studio yang dilengkapi green screen. Secara intelektual, PAR TV memiliki brand yang dikenal di kawasan Sumedang dan sekitarnya sebagai televisi yang mengedepankan nilai seni, budaya, dan kearifan lokal Sunda. Selain itu, $P A R T V$ juga memiliki izin siaran dan kerjasama yang baik dengan pengiklan yang terdiri dari kalangan sekolah sekitar, pemerintah daerah Sumedang bahkan Majalengka.

Dari sumber daya manusia $P A R T V$ memiliki 13 orang pekerja dari latar belakang pendidikan yang berbeda-beda namun diberi pelatihan secara rutin. Seluruh pekerja di PAR $T V$ adalah orang Sunda. Hal ini dapat membantu dalam penggarapan program yang bermuatan kearifan lokal. Dari sisi keuangan, $P A R T V$ mendapatkan penghasilan dari iklan dan liputan berbayar. Penghasilan tersebut dinilai cukup, dibuktikan dengan masih eksisnya $P A R T V$ hingga saat ini dan kesejahteraan SDM. Pasalnya, menurut Windu Mandela, penghasilan karyawan $P A R T V$ lebih besar dari penghasilan karyawan di TV lokal lainnya di Sumedang. Berdasarkan wawancara dengan Septian Mulyana seorang mantan karyawan di JMTV, karyawan JMTV 
Volume 03 Nomor 02 Tahun 2020

DOI: $10.24198 / j k j . v 3 i 2.23793$

hanya digaji Rp 700.000 per bulan. Sedang menurut Fahmi Amirullah, karyawan SKTV diupah Rp 1.500.000 per bulan. Walaupun pihak $P A R T V$ tidak menyebutkan nominal upah perbulan namun dapat dipastikan upah karyawan $P A R T V$ lebih dari Rp 1.500 .000 per bulannya.

\section{Key Activities}

Aktivitas kunci memiliki tiga tipe yaitu kegiatan produksi (production), penyelesaian masalah (problem solving), dan jaringan (platform/network). Dalam hal ini PAR TV memiliki aktivitas kunci tipe produksi dimana kegiatan produksi program yang menjadi key aktivity-nya. (Osterwalder 2010: 37).

\section{Key Partnerships}

Sejauh ini PAR TV melakukan kerjasama dengan $E O$ setempat dalam mendapatkan informasi mengenai acara-acara yang dapat diliput. Selain itu, PAR TV juga melakukan kerjasama dengan pemerintah daerah untuk mengiklankan kegiatan mereka. Bahkan, PAR TV juga sempat melakukan kerjasama dengan pemerintah Sumedang dalam bentuk program khusus bernama Parlementaria pada 2018. Dalam hal joint venture, PAR TV melakukan kerjasma dengan Antara $T V$ untuk menayangkan sebuah program paketan mengenai lingkungan yang berjudul Bumi Hijau.

\section{Cost Structure}

$P A R T V$ menggunakan struktur pembiayaan cost driven. Sedapat mungkin PAR TV menekan biaya produksi agar tidak terlalu besar. Penggunaan model bisnis kanvas dalam penelitian ini diilhami oleh sebuah skripsi terdahulu berjudul Strategi Manajemen Radar Tasikmalaya TV dalam Mempertahankan Eksistensinya. Penelitian yang ditulis oleh Regina Heryadi ini membahas tentang strategi Radar Tasikmalaya $T V$ dalam bertahan di industri media sebagai satu-satunya televisi lokal di Priangan Timur.

Regina menemukan SDM Radar Tasikmalaya TV yang jumlahnya sedikit tidak menjadi masalah besar karena mereka memiliki berbagai skill. Hal ini juga ditemukan di PAR TV yang hanya memiliki 13 pekerja namun pekerjaan media tetap bisa berjalan lancar. Selain itu, sumber penghasilan Radar Tasikmalaya $T V$ pun sama dengan $P A R T V$ yaitu dari iklan dan program. Bedanya, Radar Tasikmalaya TV tidak memiliki marketing khusus sedang PAR TV memiliki pekerja yang khusus mengurusi marketing. Kesamaan lainnya, kedua media ini sama-sama melakukan kerjasama dengan event organiser. Namun, Radar Tasikmalaya TV belum memiliki izin penyelenggara penyiaran sedangkan PAR TV sudah memilikinya sejak 2012.

\section{Dari Segi Produksi Konten}

Konten bermuatan seni, budaya, dan kearifan lokal menjadi senjata utama yang digunakan PAR TV untuk mempertahankan eksistensinya dari dulu hingga kini. Program seni, budaya, dan kearifan lokal ini dapat dipengaruhi oleh dua faktor yaitu faktor dari luar dan faktor dari dalam. Untuk mengetahui faktor-faktor tersebut, peneliti menggunakan teori hieararchy of influence atau pengaruh hirarki dari Pamela J. Shoemaker dan Stephen D. Reese (Shoemaker PJ, 1996). Teori Hierarchy of Influence merupakan teori untuk memahami isi media. Shoemaker dan Stephen D. Reese membagi pengaruh-pengaruh dalam lima level yaitu individu pekerja media, rutinitas media, organisasi media, luar media, dan ideologi. Shoemaker dan Reese memiliki pandangan bahwa media bukan hanya medium yang pasif (media as channels) melainkan media memiliki peran aktif dalam membentuk realitas (media as participants). 
DOI: $10.24198 /$ jkj.v3i2.23793

\section{Level Individu}

PAR TV memiliki pekerja atau individu-individu yang memiliki latar belakang pendidikan yang berbeda-beda. Namun, latar belakang suku mereka sama yaitu dari suku Sunda. Hal ini secara tidak langsung dapat mempengaruhi program-program yang bermuatan kearifan lokal. Tentunya program kearifan lokal akan sangat baik jika digarap oleh orang-orang lokalnya sendiri. Dengan demikian, program bermuatan lokal PAR TV tidak sekadar menyajikan tayangan yang disisipkan unsur lokal di dalamnya namun juga disampaikan dengan bahasa bahkan aksen yang kental khas Sunda. Hal kecil seperti aksen ini tampaknya dapat menambah nilai kedekatan pada khalayak.

\section{Rutinitas Media}

Media rutin dibentuk oleh tiga unsur yaitu sumber berita, organisasi media, dan khalayak. Sumber berita adalah orang-orang yang memberikan pernyataan atau informasi yang didapatkan dan digunakan media untuk membuat berita. Sedangkan, organisasi media dapat disebut sebagai redaksi yang mengemas pemberitaan yang akan didistribusikan kepada khalayak. Terakhir, khalayak adalah sekumpulan orang-orang yang menerima berita yang dibuat media atau dapat disebut sebagai sasaran berita.

Unsur khalayak disebut berpengaruh terhadap level media rutin karena pada dasarnya berita dibuat untuk disajikan kepada khalayak. Dengan demikian, media harus menyesuaikan produk-produk mereka dengan kebutuhan dan keinginan khalayak. Berita yang baik adalah berita yang mengandung nilai-nilai berita seperti nilai penting, besar, aktual, kedekatan, keunikan, menyentuh kemanusiaan, dan kontroversi.

Dalam memproduksi konten bermuatan seni, budaya, dan kearifan lokal, PAR TV sudah menerapkan rutinitas media yang mengacu pada keinginan dan kebutuhan khalayak. Tidak hanya dalam penyajian berita khas seperti program Budaya Urang, PAR TV juga menyediakan program berita dengan menggunakan bahasa Sunda yaitu Beja Keur Balarea. Dengan demikian, informasi-informasi penting dan menarik dapat disampaikan dengan baik kepada khalayak karena lebih mudah dimengerti.

\section{Organisasi Media}

Secara organisasi, PAR TV adalah salah satu anak dari perusahaan media bernama Geomedia yang bernaung di bawah badan hukum PT. Indonesia Milik Kita. Adapun visi Geomedia sebagai berikut:

"Menjadi kelompok usaha media yang menjadi referensi bagi masyarakat Indonesia untuk mendapatkan informasi yang akurat dan terpercaya, tidak berpihak dan independen, mampu menyandingkan disiplin jurnalisme dan aktivisme sosial sekaligus berkontribusi bagi pemberdayaan masyarakat Indonesia". (Geomedia, 2011)

Sedangkan, misi Geomedia adalah:

"Menyebarluaskan berbagai ide, pemikiran, peristiwa di segala aspek dalam kehidupan masyarakat di negara Indonesia. Rujukan bagi masyarakat dalam memperoleh informasi aktual dan berimbang. Menyuguhkan konten informasi hiburan yang mendidik dan mencerdaskan. Menjadi bagian dalam pertumbuhan industri kreatif melalui servis dan layanan serta kerjasama yang mengutamakan ide, kreatifitas, dan profesionalisme. (Geomedia, 2011).

Visi dan misi Geomedia tentunya berpengaruh terhadap isi PAR TV. Jika visi PAR TV salah satunya adalah menyajikan berita yang tidak berpihak dan independen hal ini dirasa 
kurang tepat. Pasalnya, seluruh karyawan $P A R T V$ tunduk pada peraturan dan keinginan pemilik media. Contohnya dalam sebuah program berbayar, tentu saja $P A R T V$ berpihak pada pengiklan yang membayar mereka.

Kebijakan-kebijakan organisasi yang dirasa berpengaruh positif terhadap kelangsungan program seni, budaya, dan kearifan lokal PAR TV adalah komunikasi yang baik dengan barisan eksekutif/pimpinan. Semua yang dikerjakan, biaya produksi, dan pemilihan topik harus dilaporkan terlebih dahulu ke pimpinan. Hal ini membantu pengawasan dan mengurangi risiko kesalahpahaman dalam media.

\section{Luar Media}

Pengaruh luar media dapat berasal dari sumber berita, hubungan masyarakat, pengiklan dan penonton, pemerintah, pangsa pasar dan teknologi. Sumber berita dirasa sangat penting karena sumber berita adalah orang yang dapat memberikan informasi inti untuk pembuatan berita. Di sini wartawan hanya dapat "meminjam mulut" dan tidak bisa menuliskan opininya. Begitu pula pengiklan dan khalayak disebut sangat mempengaruhi media karena mereka adalah sumber kehidupan bagi media. Tayangan yang disajikan media tentunya mengikuti permintaan khalayak dan pengiklan. Contohnya, iklan rokok tidak mungkin ditayangkan di sela-sela program khusus untuk anak.

Pengaruh besar pun datang dari pemerintah yang berhak mengontrol atau memberhentikan sebuah program yang dirasa bertentangan dengan norma dan nilai yang berlaku di masyarakat. Pembatasan ini biasanya berupa undang-undang yang mengatur seperti P3SPS. Usur lainnya adalah pangsa pasar, unsur ini disebut berpengaruh karena pada dasarnya media didirikan untuk bisnis dan melakukan kompetisi dengan media lainnya untuk mendapatkan pelanggan dan penonton. Hal ini menuntut media untuk membuat konten sekreatif mungkin. Terakhir unsur teknologi, dimana unsur ini tentu berpengaruh terhadap isi media karena teknologi dapat mempermudah kinerja media. Misal dalam kegiatan transfer data atau promosi di internet.

Program $P A R T V$ yang kebanyakan bermuatan kearifan lokal dipengaruhi oleh khalayaknya yang hanya berasal dari wilayah Parahyangan. Untuk menekankan nilai kedekatan, PAR TV hanya membuat berita dan tayangan seputar peristiwa yang terjadi di Jawa Barat. Karena itu, sumber berita atau narasumber pun berasal dari Jawa Barat. Kekhususan tersebut membuat pengiklan yang pangsa pasarnya masyarakat Parahyangan saja (bukan masyarakat nasional), lebih memilih mengiklan di $P A R T V$. Selain tarifnya lebih murah dari televisi nasional, jangkauan $P A R T V$ pun dirasa cukup untuk mencapai pasarnya.

\section{Level Ideologi}

Level ini menceritakan tentang ide-ide atau gagasan yang ada di dalam sebuah media. Level ini bersifat abstrak dan biasanya tidak disadari oleh khalayak. Sebetulnya tujuan utama $P A R T V$ adalah bisnis, namun di sisi lain $P A R T V$ juga memiliki tujuan untuk melestarikan seni dan budaya Sunda melalui tayangan-tayangan program di televisi. Sasaran utama PAR TV adalah anak-anak muda yang di zaman sekarang ini rentan melupakan budayanya sendiri dan lebih tertarik pada budaya barat. (Wawancara Soni, Humas PAR TV 4 April).

Memfokuskan konten pada seni, budaya, dan kerifan lokal adalah salah satu strategi yang juga dipakai di televisi-televisi lokal Jogjakarta. Dalam penelitian terdahulu berjudul Mediating the Local: Representing Javanese Cultures on Local Television in Indonesia. Penelitian yang ditulis oleh Els Bogaerts dari Leiden University pada 2017 ini berfokus pada strategi manajemen yang digunakan televisi-televisi lokal di Jogjakarta dan sekitarnya. Hasil dari penelitian ini adalah (1) melokalkan format yang global, (2) mengedepankan tayangan seni budaya lokal, dan (3) membuat kerjasama dengan artis lokal dan khalayak lokal (Bogaerts, 
2017). Strategi serupa juga diterapkan dalam sebuah penelitian berjudul Analisis Deskriptif Program MQTV Sebagai Media Dakwah yang ditulis Yaser Mubarok dan Dasrun Hidayat dari Universitas BSI Bandung. Yaser dan Dasrun meneliti tentang MQTV atau Manajemen Qolbu Televisi yang benar-benar fokus membahasa dakwah.

Proposisi $M Q T V$ sebagai media dakwah ternyata bukan sekadar proposisi semata melainkan pada kenyataannya televisi tersebut memfokuskan diri untuk membahas konten bermuatan agama Islam. Seluruh konten yang mengandung komunikasi dakwah disajikan dengan format yang berbeda-beda seperti film animasi, drama, dan non drama. Dengan demikian, siraman rohani tidak terasa monoton dan menjadi lebih ringan namun tetap memiliki nilai keagamaan. Pemfokusan atau pengkhususan tayangan ini membuat $M Q T V$ menjadi televisi yang memiliki keunikan tersendiri. Strategi ini berhasil membuat $M Q T V$ bertahan sejak 2002 hingga kini.

Strategi pemfokusan isi konten tentu bukan satu-satunya hal yang dilakukan $M Q T V$. Pasalnya, televisi dakwah ini memperkuat tayangannya dengan menyasar berbagai kalangan usia. MQTV memiliki sebuah program yang diperuntukkan anak-anak usia dini yaitu MQids yang menayangkan lagu-lagu islami untuk anak (Mubarok, 2014). Menyasar kalangan anak usia dini nampaknya belum dilakukan oleh PAR TV. Padahal, seni, budaya, dan kearifan lokal Sunda harus ditanamkan sejak dini.

\section{Dari Segi Peningkatan Kualitas Siaran}

Tabel 2. Matriks Analisis SWOT PARTV.

\begin{tabular}{|c|c|c|}
\hline EFAS & $\begin{array}{l}\text { STRENGTHS (S) } \\
\text { 1. Cakupan siaran luas. } \\
\text { 2. Sumber daya manusia diberi } \\
\text { pelatihan khusus kejurnalistikan } \\
\text { secara rutin. } \\
\text { 3. Menjunjung tinggi nilai lokalitas } \\
\text { dengan menggunakan bahasa Sunda } \\
\text { dalam penyajian berita dan beberapa } \\
\text { program lainnya. } \\
\text { 4. Menyajikan konten yang tidak bisa } \\
\text { didapatkan di televisi nasional. } \\
\text { 5. Mampu menjalin kerjasama yang } \\
\text { baik dengan pelanggan. } \\
\text { 6. Mampu menjaga kualitas program } \\
\text { dibuktikan dengan penghargaan- } \\
\text { penghargaan yang didapatkan. } \\
\text { 7. Penghasilan karyawan lebih besar } \\
\text { dari TV lainnya di Sumedang. }\end{array}$ & $\begin{array}{l}\text { WEAKNESSES (W) } \\
\text { 1. Variasi program terbatas (tidak } \\
\text { bisa menyajikan program nasional } \\
\text { apalagi internasional). } \\
\text { 2. PARTV belum mampu live di tempat } \\
\text { kejadian perkara karena belum } \\
\text { memiliki peralatan yang menunjang } \\
\text { live report. } \\
\text { 3. PAR TV belum optimal dalam } \\
\text { menggunakan media sosial. } \\
\text { 4. Jumlah SDM sedikit. }\end{array}$ \\
\hline $\begin{array}{l}\text { OPPORTUNITIES (O) } \\
\text { 1. Banyak dinas-dinas yang bisa diajak } \\
\text { kerjasama dengan PAR TV. } \\
\text { 2. Masih banyak seni, budaya, dan } \\
\text { kearifan lokal Sunda yang bisa } \\
\text { diangkat. }\end{array}$ & $\begin{array}{l}\text { STRATEGI SO } \\
\text { 1. Ikut serta dalam ajang KPID } \\
\text { Awards. } \\
\text { 2. Melakukan promosi layanan iklan } \\
\text { dengan tawaran menarik di hari-hari } \\
\text { besar. } \\
\text { 3. Melakukan observasi ke sanggar } \\
\text { seni atau pegiat seni Sunda }\end{array}$ & $\begin{array}{l}\text { STRATEGI WO } \\
\text { 1. Mengoptimalkan penggunaan media } \\
\text { sosial untuk promosi program dan } \\
\text { layanan. } \\
\text { 2. Membuat perencanaana anggaran } \\
\text { dan membuat proposal untuk pusat } \\
\text { perihal pelengkapan alat. } \\
\text { 3. Tidak membuat program nasional } \\
\text { melainkan cara-cara produksinya } \\
\text { mengacu pada televisi swasta } \\
\text { nasional. } \\
\text { 4. Memberikan pelatihan rutin } \\
\text { terghadap SDM. }\end{array}$ \\
\hline $\begin{array}{l}\text { THREATS }(\mathbf{T}) \\
\text { 1. Semakin banyaknya khalayak yang } \\
\text { berpindah pada televisi digital. } \\
\text { 2. Generasi muda yang mulai } \\
\text { melupakan budaya Sunda. } \\
\text { 3. Media lain. }\end{array}$ & $\begin{array}{l}\text { STRATEGI ST } \\
\text { 1. Mulai mempersiapkan dan } \\
\text { mempelajari mengenai era } \\
\text { digitalisasi. } \\
\text { 2. Menyajikan tayangan seni budaya } \\
\text { dengan kemasan ringan dan } \\
\text { menarik. }\end{array}$ & $\begin{array}{l}\text { STRATEGI WT } \\
\text { 1. Rajin berkomunikasi dengan } \\
\text { khalayak melalui media sosial. } \\
\text { 2. Tidak mencari variasi program yang } \\
\text { bukan termasuk dalam lingkaran } \\
\text { segmentasinya. }\end{array}$ \\
\hline
\end{tabular}

Sumber: Peneliti. 
Volume 03 Nomor 02 Tahun 2020

DOI: $10.24198 / j k j . v 3 i 2.23793$

\section{Keterangan:}

1. Matrik Analisis SWOT: Alat yang dipakai untuk menyusun faktor-faktor strategis perusahaan.

2. EFAS: Faktor strategi eksternal.

3. IFAS: Faktor strategi internal.

4. Strenghts (S): Kekuatan yang dimiliki PAR TV.

5. Weaknesses (W): Kelemahan yang dimiliki PAR TV.

6. Opportunities $(O)$ : Peluang yang dimiliki $P A R T V$.

7. Threats (T): Ancaman yang dimiliki PAR TV.

8. Strategi SO: Strategi penggunaan kekuatan $P A R T V$ untuk memanfaatkan peluang.

9. Strategi WO: Strategi untuk meminimalkan kelemahan guna memanfaatkan peluang.

10. Strategi ST: Strategi penggunaan kekuatan untuk mengatasi ancaman.

11. Strategi WT: Strategi meminimalisir kelemahan dan menghindari ancaman.

Strategi PAR TV dalam meningkatkan kualitas siaran akan dianalisis menggunakan analisis SWOT (Strenght, Weakness, Opportunity, dan Threat). Analisis ini berguna untuk mengenali kekuatan, kelemahan, peluang, dan ancaman yang menentukan kinerja perusahaan. (Nisak, 2004).

Matriks analisis SWOT di atas menyebutkan strategi-strategi $P A R T V$ dalam meningkatkan kualitas siarannya. Strategi-strategi tersebut dibagi ke dalam empat bagian yaitu strategi SO, strategi WO, strategi ST, dan strategi WT. SO adalah strategi PAR TV dalam menggunakan kekuatannya untuk mendapatkan peluang. Sejauh ini kekuatan $P A R T V$ antara lain: Cakupan siaran yang luas dapat membuat pengiklan tertarik untuk mengiklan karena produk mereka dapat terpasarkan dengan baik dan merata jika dibandingkan mengiklan di televisi lokal lainnya di Sumedang.

Sumber daya manusia diberi pelatihan khusus kejurnalistikan secara rutin. Dengan demikian, SDM dibekali dengan skill kejurnalistikan atau broadcasting walaupun mereka bukan berasal dari sekolah jurnalistik. Menjunjung tinggi nilai lokalitas dengan menggunakan bahasa Sunda dalam penyajian berita dan beberapa program lainnya. Hal ini dapat menambah nilai kedekatan kepada penonton yang secara umum berasal dari wilayah Parahyangan. Menyajikan konten yang tidak bisa didapatkan di televisi nasional. PAR TV memiliki positioning yang sangat khusus sehingga kontennya pun khusus, fokus, dan unik.

Mampu menjalin kerjasama yang baik dengan pelanggan. PAR TV dewasa ini memiliki hubungan yang baik dengan pengiklan. Acap kali mereka diminta meliput sebuah acara oleh sekolah atau pemerintah daerah di Sumedang, Bandung, dan Majalengka. Kemampuan menjaga kualitas program dibuktikan dengan penghargaan-penghargaan yang didapatkan. PAR TV acap kali masuk ke dalam nominasi dan bahkan memenangkan penghargaan di ajang KPID Awards.

Kekuatan-kekuatan tersebut dapat digunakan sebagai alat untuk mendapatkan peluang. Berikut peluang yang dimiliki $P A R T V$ : Banyak dinas-dinas yang bisa diajak kerjasama dengan $P A R T V$, contohnya dinas budaya dan pariwisata, dinas pendidikan, lembaga pendidikan daerah, dan masih banyak lagi. Masih banyak seni, budaya, dan kearifan lokal Sunda yang bisa diangkat. Seni budaya Sunda yang belum pernah diangkat media bisa diperkenalkan ke publik. Tak hanya itu, setiap perkembangan seni dan budaya pun bisa diberitakan. Akulturasi atau percampuran seni yang melahirkan seni baru pun patut diangkat.

Dalam menggunakan kekuatan untuk mencapai peluang, PAR TV dapat melakukan strategi SO sebagai berikut: Ikut serta dalam ajang KPID Awards untuk mengetahui penilaian para ahli media mengenai program $P A R T V$ yang diikutsertakan. Jika menang, PAR TV dapat membawa pulang hadiah dan diakui eksistensinya. Jika kalah, $P A R T V$ dapat belajar dan mengetahui apa 
saja kekurangannya. Melakukan promosi layanan iklan dengan tawaran menarik di hari-hari besar. Promosi ini telah dilakukan $P A R T V$ dan harus dilakukan secara terus menerus. PAR TV dapat memberikan tawaran-tawaran menarik seperti paket penayangan iklan sebanyak 15 kali untuk harga 1.500.000 saja. Promo ini dilakukan pada 17 Agustus dalam rangka memperingati HUT RI. Di hari-hari besar lainnya pun $P A R T V$ dapat melakukan strategi serupa. Melakukan observasi ke sanggar seni atau pegiat seni Sunda. $P A R T V$ melakukan penyisiran mengenai sanggar-sanggar seni lokal yang melestarikan sebuah kesenian. Dengan survei dan wawancara pegiat seni, $P A R T V$ dapat mengetahui sejarah, perkembangan, permasalahan, dan bahkan jenis seni lainnya.

Di sisi lain, $P A R T V$ juga masih memiliki kelemahan, di antaranya: Menurut Windu, variasi program $P A R T V$ terbatas (tidak bisa menyajikan program nasional apalagi internasional). Tidak seperti televisi nasional yang bisa menayangkan berita apapun di seluruh Indonesia, $P A R$ $T V$ harus lebih memperhatikan segmentasi yang ditetapkan. PAR TV harus mempertimbangkan siapa saja yang akan mengkonsumsi konten dan apa saja konten yang cocok untuk dikonsumsi khalayaknya.

PARTV belum mampu live di tempat kejadian perkara karena belum memiliki peralatan yang menunjang live report. Hingga saat ini $P A R T V$ belum mampu menayangkan live report selain siaran langsung di studio. PAR TV belum optimal dalam menggunakan media sosial. Kebanyakan media sosial yang dimiliki PAR TV terbengkalai, pihak PAR $T V$ tidak rajin dalam menggunakan media sosial padahal media sosial bisa sangat bermanfaat.

Kelemahan ini dapat diminimalisir mengunakan strategi WO. Strategi ini berguna untuk meminimalisir kelemahan agar peluang bisa tercapai. Berikut strategi WO PAR TV: Mengoptimalkan penggunaan media sosial untuk promosi program dan layanan. Membuat perencanaan anggaran dan membuat proposal untuk pusat perihal pelengkapan alat. Tidak membuat program nasional melainkan cara-cara produksinya mengacu pada televisi swasta nasional.

PAR TV juga memiliki beberapa ancaman sebagai berikut: Semakin banyaknya khalayak yang berpindah pada televisi digital. Generasi muda yang mulai melupakan budaya Sunda. Untuk mencegah ancaman tersebut, $P A R T V$ harus memiliki strategi ST yaitu menggunakan kekuatan untuk mencegah ancaman.

Berikut strategi ST PAR TV: Mulai mempersiapkan dan mempelajari mengenai era digitalisasi. Menyajikan tayangan seni budaya dengan kemasan ringan dan menarik seperti menyertakan contoh anak-anak muda yang ikut andil dalam pelestarian suatu seni atau budaya.

PAR TV juga harus mempertimbangkan strategi WT atau strategi untuk meminimalisir kelemahan dan menghindari ancaman. Berikut strategi WT PAR TV: Rajin berkomunikasi dengan khalayak melalui media sosial. PAR TV dapat mengunggah informasi-informasi singkat dan ringan, berupa tulisan, gambar, atau video yang mudah dikonsumsi oleh warga net yang kebanyakan adalah anak muda. Tidak mencari variasi program yang bukan termasuk dalam lingkaran segmentasinya. Namun, harus mengoptimalkan program yang ada dan menyajikannya dengan cara yang menarik serta dapat dikonsumsi oleh semua kalangan.

\section{Strategi Manajemen PAR TV Sumedang}

Jika melihat bagan di atas maka dapat diuraikan bahwa PAR TV menggunakan strategi sebagai berikut: Memilih segmentasi sesuai proximity, kebutuhan, dan pendapatan khalayak. Memberi nilai informasi, hiburan, dan edukasi yang menitik beratkan pada proximity. Menggunakan saluran dengan jangkauan yang luas dan pemanfaatan sosial media. Menjalin dua tipe hubungan, langsung dan tak langsung tergantung tipe pelanggan. Menawarkan jasa iklan dengan tipe pembayaran satu kali bayar. Mengembangkan sumberdaya intelektual, fisikal, 
dan SDM secara berkala. Menjalankan tipe produksi sebagai aktivitas kunci. Bekerjasama dengan pemerintah, EO, dan lembaga setempat. Menekan biaya produksi seminimal mungkin dengan menghindari narasumber yang meminta bayaran.

Bagan 1 Strategi Manajemen $P A R T V$ Sumedang.

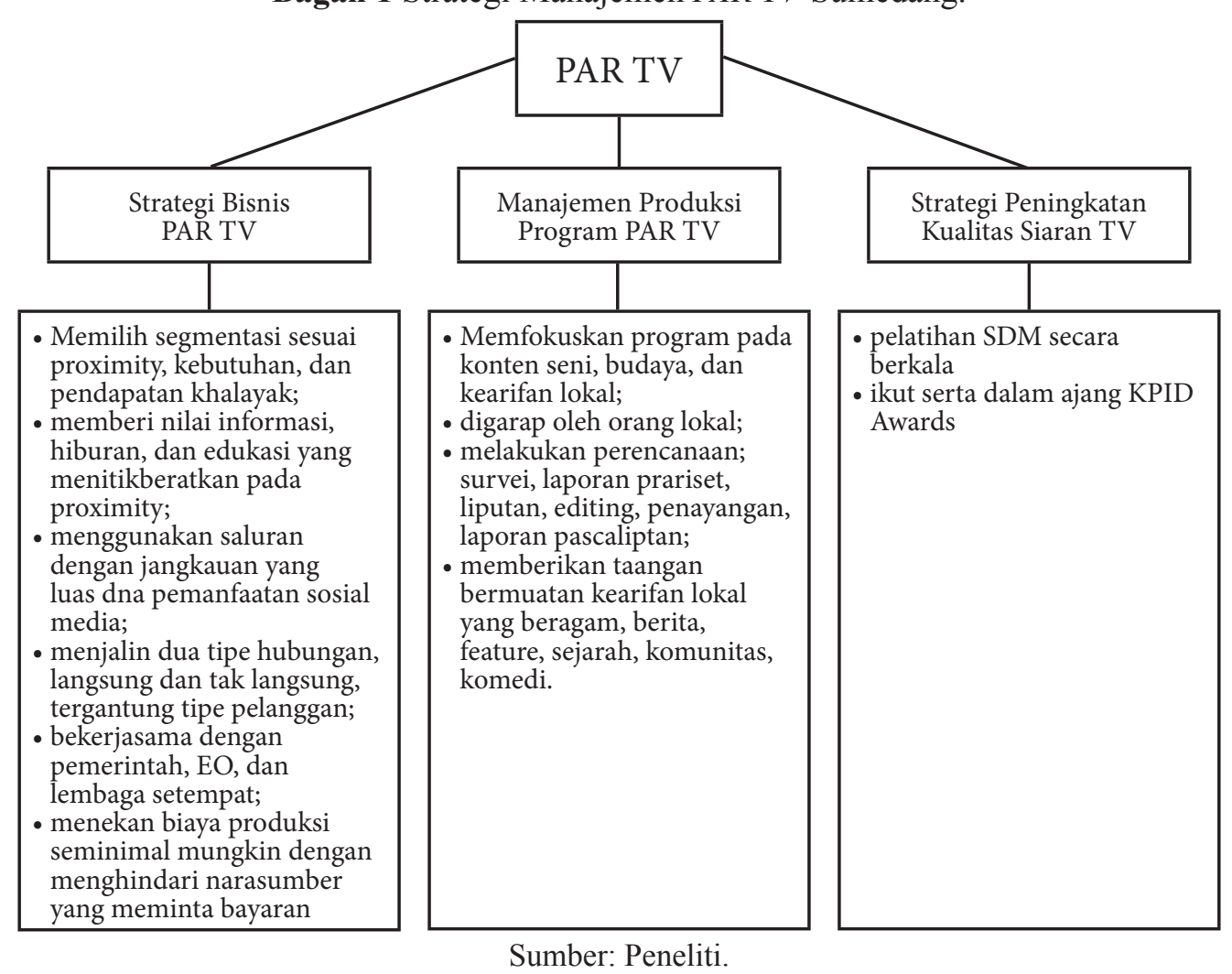

Selanjutnya, media harus mempertimbangkan strategi manajemen yang mencakup manajemen produksi, manajemen iklan, struktur organisasi, hingga penentuan kultur kerja. Dalam memproduksi program bermuatan seni, budaya, dan kearifan lokal PAR TV menggunakan strategi sebagai berikut: Memfokuskan program pada konten seni, budaya, dan kearifan lokal. Digarap oleh orang lokal. Melakukan perencanaan, survei, laporan prariset, liputan, editing, penayangan, laporan pascaliputan.

Setelah strategi manajemen ditentukan dan berjalan, maka media harus sudah memiliki strategi peningkatan kualitas siaran agar layak dikonsumsi oleh penonton. Kualitas program atau siaran yang baik akan membuat penonton dapat menikmati tayangan tersebut. Banyaknya jumlah penonton tentunya berpengaruh terhadap pengiklan. Berikut strategi peningkatan kualitas siaran yang digunakan $P A R T V$ :

Pelatihan SDM dilakukan secara berkala. Pimpinan pusat sangat memperhatikan PAR $T V$ dan kinerjanya. Komunikasi yang baik tentunya memudahkan pusat untuk melakukan pengawasan. Pusat juga selalu mengirim ahli media untuk member arahan pada SDM PAR TV. Ikut serta dalam ajang KPID Awards guna mendapatkan pengakuan atau pelajaran mengenai kekurangan apa saja yang harus diperbaiki $P A R T V$ dalam program yang diikutsertakan.

Seluruh kebijakan media yang dibuat oleh $P A R T V$ sebagai media lokal ini tentunya di bawah persetujuan pimpinan atau pemilik media. Anak media tidak dapat melakukan apapun tanpa adanya "lampu hijau" dari pimpinan atau pemilik media. Pada akhirnya seluruh strategi yang dibangun itu bertujuan untuk mendapatkan laba sebanyak-banyaknya karena prioritas utama anak media sebagai media lokal adalah bisnis (Nasihudin, 2019). 
DOI: $10.24198 /$ jkj.v3i2.23793

\section{SIMPULAN}

Strategi bisnis $P A R T V$ antara lain memilih segmentasi sesuai proximity, kebutuhan, dan pendapatan khalayak, memberi nilai informasi, hiburan, dan edukasi yang menitik beratkan pada proximity. Menggunakan saluran dengan jangkauan yang luas dan pemanfaatan sosial media. Menjalin dua tipe hubungan langsung dan tak langsung tergantung tipe pelanggan. Menawarkan jasa iklan dengan tipe pembayaran satu kali bayar, bekerjasama dengan pemerintah, EO, dan lembaga setempat, serta menekan biaya produksi seminimal mungkin dengan menghindari sumber berita yang meminta bayaran.

Proses produksi konten bermuatan seni, budaya, dan kearifan lokal PAR TV dilakukan dalam 7 tahap yaitu penentuan topik/perencanaan, survei, laporan (praliputan) pembiayaan dan persetujuan pusat, peliputan, editing, penayangan, dan laporan pasca liputan. Program difokuskan pada konten bermuatan seni, budaya dan kearifan lokal dalam bentuk tayangan yang beragam dan digarap langsung oleh pekerja lokal.

Dalam meningkatkan kualitas siarannya, PAR $T V$ ikut serta dalam ajang KPID Awards guna mendapat penilaian dan dapat memperbaiki kekurangannya. Pusat juga memberikan pelatihan dan controlling secara rutin bagi para karyawannya.

Jadi secara umum, strategi manajemen utama yang sangat mempengaruhi $P A R T V$ Sumedang adalah pemfokusan program-program pada konten bermuatan seni, budaya, dan kearifan lokal Sunda. Hal ini menjadi kekuatan utama PAR TV dalam mempertahankan eksistensinya hingga kini.

\section{DAFTAR PUSTAKA}

Agus. (2019). Gaji UMR Jabar Tahun 2019, Daftar Lengkap UMK 27 Kabupaten dan Kota di Jawa Barat Tahun 2019 - 2016.

Bogaerts, E. (2017). Mediating the local: Representing Javanese cultures on local television in Indonesia. Journal of Southeast Asian Studies. https://doi.org/10.1017/ S0022463417000042

Geomedia. (2011). Tentang Geomedia Grup.

Hadisaputro, S. (2018). 207 Karya Radio dan Televisi Berkompetisi di KPID Award 2018.

Herdiansyah, H. (2010). Metode Penelitian Kualitatif (untuk Ilmu-Ilmu Sosial). Jakarta: Salemba Humanika.

Hidayat, Dadang Rahmat, Ahmad A. Basith, dan H. S. M. R. (2017). Kebijakan Lembaga Penyiaran Lokal Jawa Barat Dalam Pengelolaan Program Siaran Pemilihan Gubernur Tahun 2013. Prosiding Magister Ilmu Komunikasi, 1(1).

Imanuddin, A. M. (2016). PARTV Sumedang.

Mubarok, Y. \& D. H. (2014). Analisis Deskriptif Ptogram MQTV Sebagai Media Dakwah. Jurnal, Universitas BSI., 1(2).

Nasihudin, A. (2019). Strategi Manajemen Parahayangan TV Dalam Mempertahankan Eksistensinya. Universitas Padjadjaran.

Nisak, Z. (2004). Analisis Swot Untuk Menentukan Strategi Kompetitif. Analisis Swot Untuk Menentukan Strategi Kompetitif. https://doi.org/10.1038/sc.1991.24

Osterwalder, A. (2010). Business Model Genertion (A Handbook for Visionaries, Game Changers, and Challengers) (Y. Pigneur, Ed.). New Jersey: Wiley.

Shoemaker PJ, dan S. D. (1996). Mediating the Message: Theories of Influence on Mass Media Message. London: Longman Publisher.

Sugiyono. (2010). Metode Penelitian Bisnis. Pendekatan Kuantitatif, kualitatif dan R \& D. Bandung: Alfabeta. 
Volume 03 Nomor 02 Tahun 2020

DOI: $10.24198 / j k j . v 3 i 2.23793$

Thohir, A. (2013). Sumedang "Puseur Budaya Sunda" Kajian Sejarah Lokal. Bandung: Galuh Nurani.

Viranda, L., Hidayat, D. R., \& Yudhapramesti, P. (2019). Manajemen Produk Media Kompas. com Untuk Bersaing di Era Generasi Milenial. Jurnal Kajian Jurnalisme, 2(1), 61. https://doi.org/10.24198/jkj.v2i1.21074

Yin, R. K. (1996). Studi Kasus Desain \& Metode. Jakarta: Raja Grafindo Persada. 